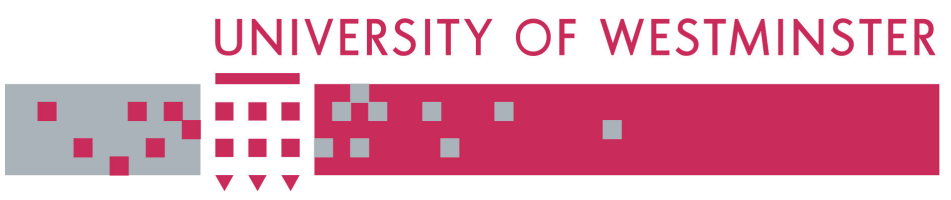

WestminsterResearch

http://www.wmin.ac.uk/westminsterresearch

\title{
Signal processing techniques for aeronautical communications via satellite.
}

\author{
Panos Fines ${ }^{1}$ \\ Katerina Christofylaki ${ }^{2}$ \\ Paul Febvre ${ }^{3}$
}

${ }^{1}$ Wireless Intelligent Systems Ltd, London

${ }^{2}$ Cavendish School of Computer Science, University of Westminster

${ }^{3}$ Inmarsat Ltd., Dept of Advanced Systems, London

Copyright (c) [2005] IEEE. Reprinted from Proceedings of the Fifth IEEE International Symposium on Signal Processing and Information Technology, 2005, pp. 507-511.

This material is posted here with permission of the IEEE. Such permission of the IEEE does not in any way imply IEEE endorsement of any of the University of Westminster's products or services. Internal or personal use of this material is permitted. However, permission to reprint/republish this material for advertising or promotional purposes or for creating new collective works for resale or redistribution must be obtained from the IEEE by writing to pubs-permissions@ieee.org. By choosing to view this document, you agree to all provisions of the copyright laws protecting it.

The WestminsterResearch online digital archive at the University of Westminster aims to make the research output of the University available to a wider audience. Copyright and Moral Rights remain with the authors and/or copyright owners. Users are permitted to download and/or print one copy for non-commercial private study or research. Further distribution and any use of material from within this archive for profit-making enterprises or for commercial gain is strictly forbidden.

Whilst further distribution of specific materials from within this archive is forbidden, you may freely distribute the URL of WestminsterResearch. (http://www.wmin.ac.uk/westminsterresearch).

In case of abuse or copyright appearing without permission e-mail wattsn@wmin.ac.uk. 


\title{
Signal Processing Techniques for Aeronautical Communications via Satellite
}

\author{
Panos Fines ${ }^{1}$, Katerina Christofylaki ${ }^{2}$, Paul Febvre ${ }^{3}$ \\ ${ }^{1}$ Wireless Intelligent Systems Ltd, 64 Hatfield House, Baltic Street, London EC1Y 0SU, U.K. \\ ${ }^{2}$ University of Westminster, Dept. Electronic Systems, 115 New Cavendish Street, London W1W 6WS, U.K. \\ ${ }^{3}$ Inmarsat Ltd, Dept. of Advanced Systems, 99 City Road, London EC1Y 1AX, U.K.
}

\begin{abstract}
Aeronautical communications are playing an important role in the air traffic control as well as new passenger communication services. Due to the global coverage required, satellite transponders provide the required links which are traditionally limited to narrowband throughputs (e.g. $64 \mathrm{~kb} / \mathrm{s})$ due to the propagation channel characteristics. This paper analyses the reasons that limit the throughput of the aeronautical satellite links and presents advanced signal processing techniques that allow satellite transceivers to break the narrowband barriers.
\end{abstract}

Keywords: Aeronautical Satellite Systems, Aeronautical Channel Modelling, Iterative Equalization.

\section{INTRODUCTION}

There is a growing need for modern data communications for aircraft passengers, crew and air-traffic control. The demand for better aeronautical communications has led to new system designs using powerful multi-beam satellites. This paper addresses the transceiver signal processing derived from detailed analysis of the propagation channel aiming to overcome the limitations of the satellite based systems. We show that the communication subsystem can be aided from the positioning and meteorological data to improve the link reliability and throughput.

The following sections, present the aeronautical propagation channel, its effects in broadband transmissions and an iterative receiver suitable for reliable broadband communications.

\section{PROPAGATION CHANNEL MODELLING AND EFFECTS}

Geostationary satellite networks are able to provide communications over vast geographical areas and as such are well suited to satisfying aeronautical communications requirements. The effective satellite coverage area is limited by the low elevation view of the satellite. Figure 1 shows an aircraft communicating via a geostationary satellite (GEO) at 20 degrees elevation angle. In order to derive an effective aeronautical transceiver system, the aeronautical satellite channel should be carefully considered. Aircraft safety considerations require high communication integrity and reliability throughout threedimensional manoeuvres. At the same time, a small antenna is required at the aircraft with very demanding mounting requirements for reducing the air resistance. The aeronautical satellite terminals operate over a wide dynamic range in order to accommodate the long-term impairments such as signal attenuation and the Doppler effects. The short-term propagation impairments such as multipath fading are equally important and they are the main reason for the moderate data speeds currently available in the aircrafts.

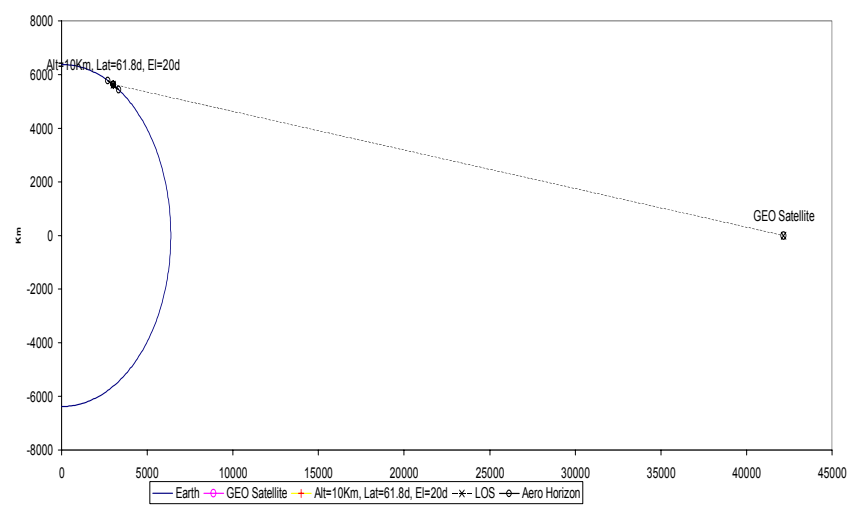

Figure 1

Figure 2 shows the physical model for most signals arriving at the airplane and demonstrates a typical geometry. Reflections from the earth surface arrive at the aeronautical antennas in addition to the line-of-sight (LOS) signal. The reflections come from the visible earth area under the aircraft (see Aero horizon in Figure 1). The multipath component (M) is the sum of many rays reflected by the earth. The ratio of the direct line of site (LOS) power $(\mathrm{C})$ to the multipath power $(\mathrm{C} / \mathrm{M})$ is a critical parameter describing the severity of the fading and, hence, the extra power required (link margin) for reliable communication. The multipath component $\mathrm{M}$ consists of the specular component and other diffused components [1], and their relative powers depend on the roughness of 
the earth's surface or the sea state (most significant flight routes are over sea) $[3,4]$.

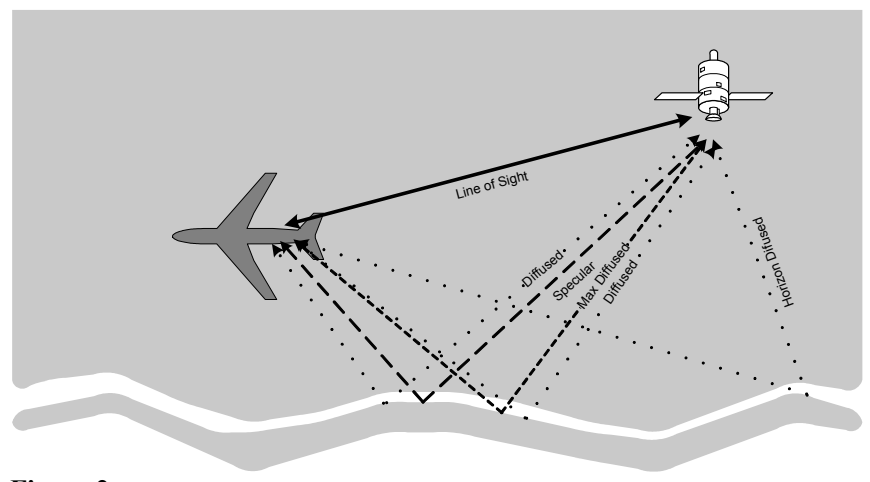

Figure 2

Another feature of the aeronautical propagation channel is that the multipath component $\mathrm{M}$ has significant delay in respect to the LOS due to the longest distance travelled bouncing on the earth's surface. In fact, $\mathrm{M}$ consists of a number of rays, the specular being the one with the shortest delay and the near horizon ones with the longest delays. In many cases, $\mathrm{M}$ is described by a continuous delay profile bounded between the shortest and longest delays and with a peak occurring at the maximum diffused component.

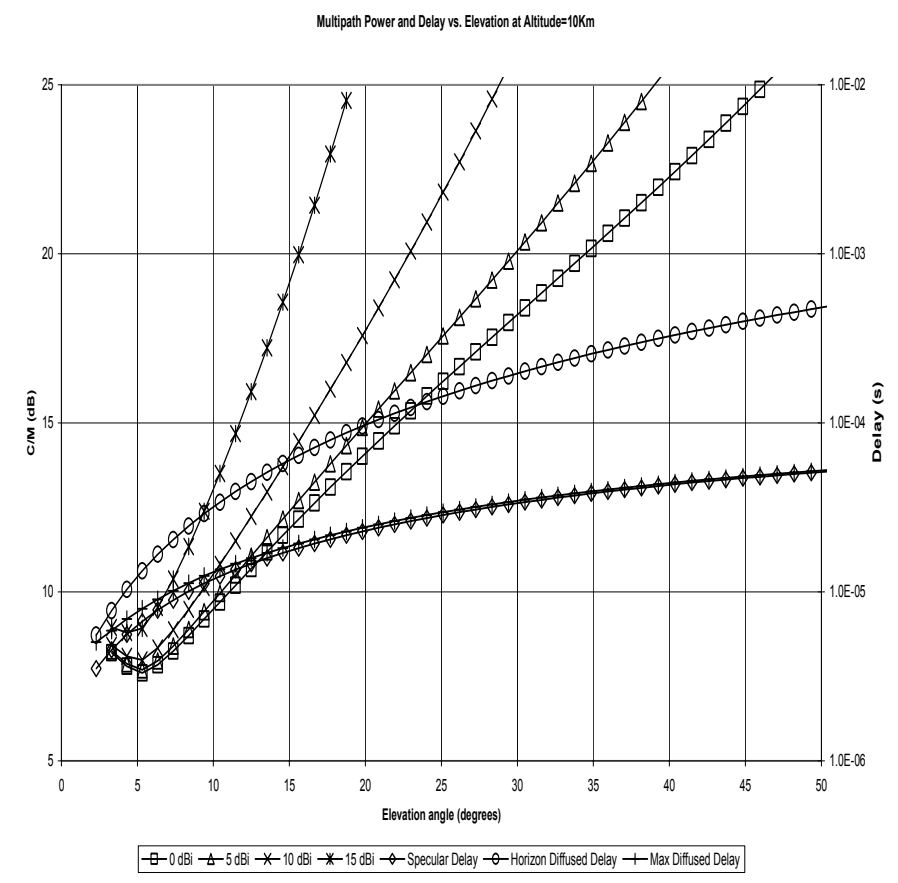

Figure 3

Figure 3 shows typical $\mathrm{C} / \mathrm{M}$ values versus the satellite elevation for different antenna gains [2], together with the minimum delayed (specular), maximum delayed (horizon) and the strongest diffused delayed components of M. The channel model used to generate these curves includes the antenna gain pattern, satellite elevation, grazing angles, sea condition, the Fresnel reflection coefficient and geometrical data $[6,7,8,11]$. In this example, the aircraft is flying over sea at an altitude of $10 \mathrm{Km}$ using L-band transmission, with a very common sea-state with waveheight of $1-3 \mathrm{~m}[2,3,5]$. For this case the non-coherent diffused component is fully developed. The shape of the multipath delay profile is in general continuous and depends on the roughness of the earth's surface, elevation angle and antenna gain profile [13]. However, in most cases the maximum multipath energy is concentrated in a narrow interval towards the specular component delay as shown in Figure 3.

Finally, both LOS and M are subject to Doppler effects. The frequency shift of the LOS is proportional to the projection of the aircraft speed vector towards the satellite. The $\mathrm{M}$ components are also shifted by the projection of the speed vector towards the reflection line, and hence, not all the reflections have the same frequency shift. In addition the $\mathrm{M}$ components are spread in frequency by typically 10 $100 \mathrm{~Hz}$ Gaussian bandwidths [13].

In this paper we shall attempt a more in-depth analysis of the multipath effects and some solutions shall be proposed. It will be shown in this paper that the aeronautical channel at low elevation angle affects the characteristics of a transmission signal in markedly different ways, depending upon the bandwidth of the transmission. Symbol rates in the range $10 \mathrm{ksym} / \mathrm{s}, 100 \mathrm{ksym} / \mathrm{s}$ and $1 \mathrm{Msym} / \mathrm{s}$ are analysed, and in the examples below QPSK transmission is assumed with $35 \%$ excess filtering resulting in total occupied bandwidths of $13.5 \mathrm{kHz}, 135 \mathrm{kHz}$ and $1.35 \mathrm{MHz}$.

The analysis above shows that the aeronautical propagation channel is fast varying and introduces time and frequency dispersion which result in severe levels of fading. As an example, an aeronautical delay profile is shown in Figure 4 as well as its effects in digital transmissions. In Figure 4 the received spectrum at the earth station or at the aircraft is distorted severely due to the delay profile. The effects are more severe as the data rate throughput is increased. For example when the transmitted spectrum is $13.5 \mathrm{kHz}$ the received signal spectrum is slightly tilted and almost unchanged. With 135 $\mathrm{kHz}$ transmitted spectrum, the received signal is subject to selective fading (one deep fade is shown). With $1.35 \mathrm{MHz}$ transmitted spectrum, the received signal spectrum is severely distorted (at least seven deep fades are shown). This observation explains why up to now the aeronautical communications were based on narrowband low data rate channels (around $64 \mathrm{~kb} / \mathrm{s}$ ). 

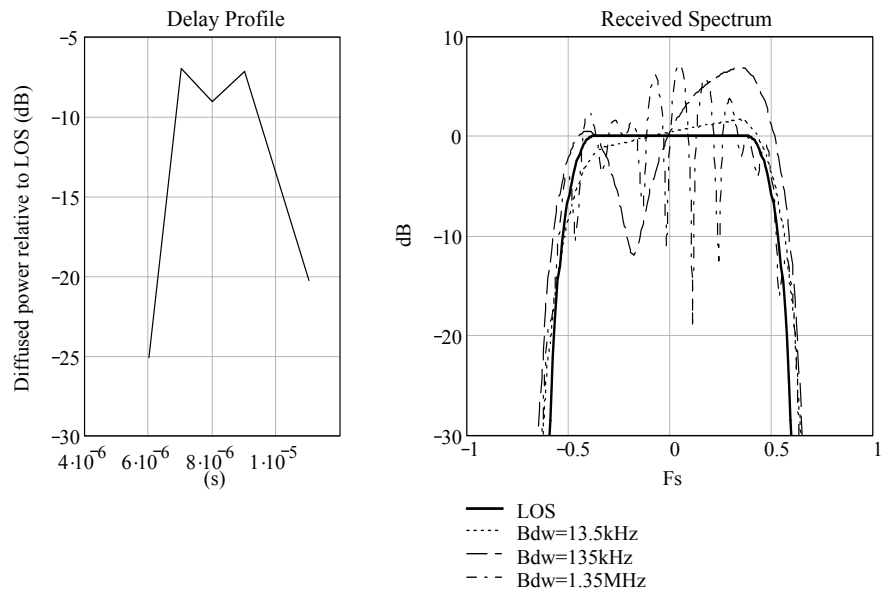

Figure 4

It can be clearly seen that the multipath components introduce flat and frequency selective fading depending on the delay spread magnitude. The multipath power can be considered as two signal degradations: one that is caused by the symbols interfering with themselves (Self Symbol Interference - SSI) contributing mostly to the flat fading case; and the other caused by symbols interfering with adjacent symbols (Intersymbol Interference - ISI) that introduces mostly selective fading. The separation is a function of the delay spread, filtering and channel rate. Figure 5 shows the separation versus the delay spread for the case where the transmission rate is $100 \mathrm{ksym} / \mathrm{sec}$ having an occupied bandwidth of $135 \mathrm{kHz}$.

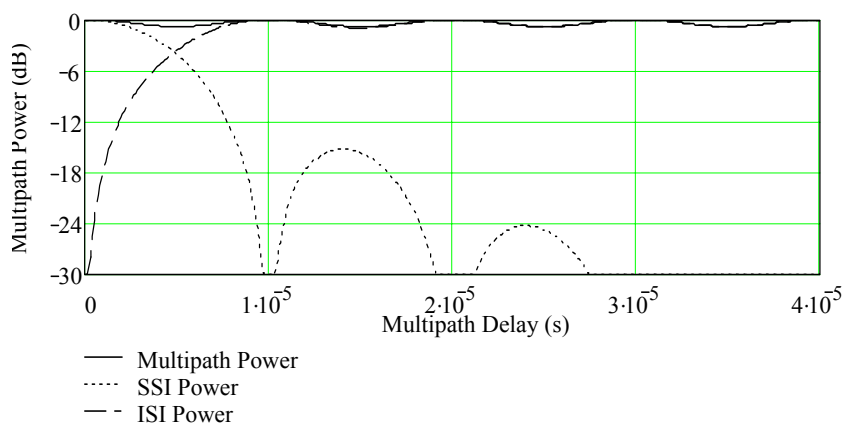

Figure 5

With the parameters selected in this example, the aeronautical channel causes both flat and frequency selective fading, with dominant degradation being dependent upon both the channel characteristics and the signal bandwidth. With $13.5 \mathrm{kHz}$ transmission bandwidth the aero channel introduces mainly flat fading and with 1.35 $\mathrm{MHz}$ transmissions mainly frequency selective fading. Clearly, if the aircraft positioning is known relative to the satellite and earth as well as meteorological data (e.g. sea roughness) many important parameters of the propagation channel can be derived and used by the communication subsystem to improve the link reliability and data throughput. This is the subject of the next section.

\section{DIGITAL COMMUNICATION SUBSYSTEM}

The flat fading can be corrected with the carrier phase tracking, automatic gain control and powerful forward error correction (FEC) combined with time diversity by interleaving. The frequency selective fading can be treated as interference contributing to the channel noise and can be treated by a conventional receiver using extensive link margin, powerful FEC and channel interleaving. However, for commercial satellite operation this is not generally an economically viable approach. A better approach is based on the observation that the frequency selective fading can be eliminated using advanced interference cancellation techniques. This requires that the receiver employs interference cancellation and/or equalization techniques. Digital receivers for high data rates usually include equalization performing three functions: channel state (significant ray) estimation, regeneration of the multipath components and cancellation of the multipath interference. The effectiveness of the equalization process depends only on the channel state and ray estimation quality since regeneration and cancellation of the interference can be precise and complete.

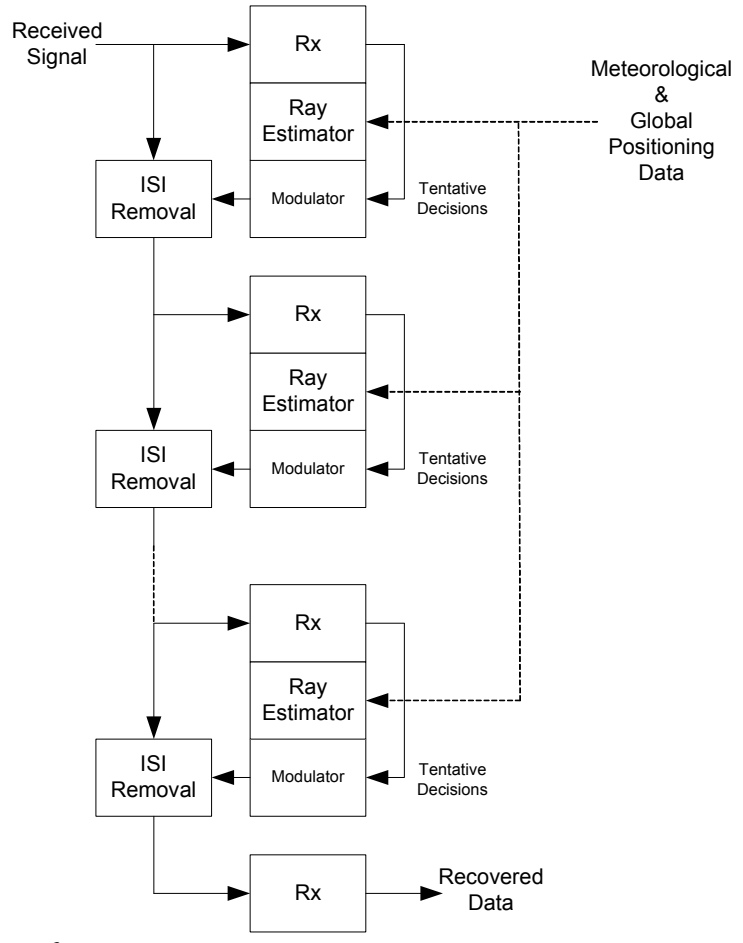

Figure 6

Figure 6 shows the architecture of a receiver that is optimised for operation with the aeronautical channel 
model, incorporating interference cancellation techniques. This architecture assumes that the transmit signal is encoded with a turbo-FEC scheme and the receiver incorporates a soft-input/soft-output iterative decoder. The $\mathrm{Rx}$ box in Figure 6 contains the demodulator and the iterative turbo decoder. The ray estimator processes the global positioning and meteorological inputs and computes the statistical $\mathrm{C} / \mathrm{M}$, delay profile and Doppler offsets. It also improves the ray estimation using the tentative data receiver outputs as reference and performs a correlation search for the multipath ray phase and amplitude. Then a replica of the estimated ISI is generated and subtracted from the incoming signal. The result is a reduced ISI signal which is then fed to an identical receiver performing again demodulation and FEC decoding. Since the receiver is now fed with reduced ISI received signals, it is performing better, i.e. more tentative decisions are reliable. The second ray estimator tries to estimate the remaining uncorrected ISI based on more reliable data. Any remaining ISI is regenerated and subtracted from the incoming signal. The described process can be repeated several times depending on the severity and spreading of the multipath interference. In each stage more ISI is removed making the data decisions more reliable. In fact, Figure 6 shows a serial interference cancellation technique which seems to perform better in the aeronautical channel compared to a parallel approach [13].

\section{PERFORMANCE RESULTS}

Having presented the aeronautical propagation channel and an iterative receiver structure in the previous sections, we now present the simulated performance results for a particular scenario. In this scenario, we have assumed a transmission rate of $100 \mathrm{ksym} / \mathrm{s}$, using QPSK with $\mathrm{a}=0.35$ roll-off Nyquist filtering occupying $135 \mathrm{kHz}$ transmit bandwidth. Furthermore we assume in this example that the forward error correction scheme employs parallel concatenated turbo coding with rate $\mathrm{R}=0.85$ (corresponding data rate is nominally $170 \mathrm{~kb} / \mathrm{s}$ ), and that the transmission consists of $2.5 \mathrm{~ms}$ long bursts with channel interleaving applied over each burst.

In Figure 7, a burst is considered as being in error when at least one bit of data is decoded incorrectly by the receiver. The ideal receiver is a receiver without any implementation loss, perfectly synchronized and operating stationary on the ground and, hence, the propagation channel is unfaded additive white Gaussian noise (AWGN). A conventional non-iterative receiver performance demonstrates a very high error floor: around $10 \%$ burst error rate due to the aeronautical propagation [10]. In Figure 7, $\mathrm{Rx}+\mathrm{Eq} 1, \ldots, 6$ denotes the iterative receiver with 1 to 6 iterations as described in the previous section and shown in Figure 6. There is a clear improvement in performance characterized by a consistent lowering of the error floor, due to the fact that at each iteration the receiver removes the propagation effects by removing clusters of strong interference from the earth (see Figure 2).

$170 \mathrm{~kb} / \mathrm{s}, \mathrm{QPSK}, \mathrm{R}=0.85, \mathrm{Bdw}=135 \mathrm{kHz}$, Altitude $=10 \mathrm{Km}$, Elevation $=5$ degrees

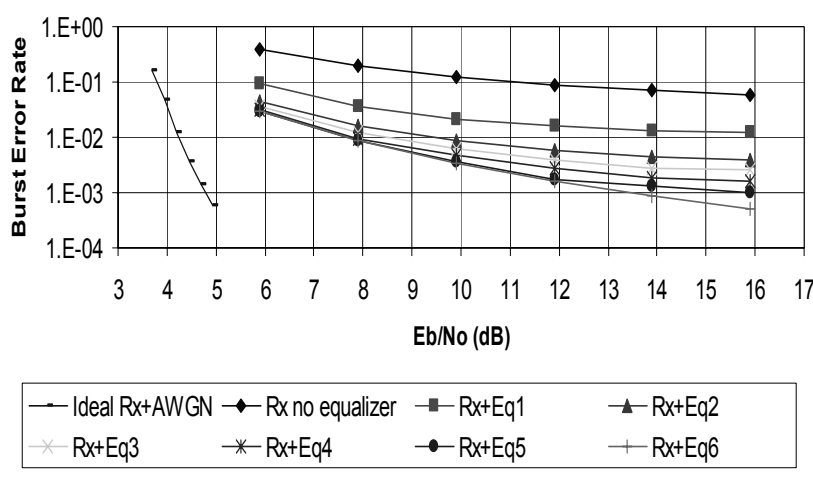

Figure 7

It appears that by sequentially removing small amounts of interference, the iterative receiver is very effective and robust: no time-slips [9] or error-floor [10] were observed. Also very important was the fact that there was no measurable loss of performance when multipath interference signals were absent (non-faded case). At higher data rates than used in this example it is expected that the receiver architecture will perform even more effectively, however it is considered that computational complexity may become an issue, which may be addressed by reducing the number of iterations.

\section{CONCLUSIONS}

We have presented the aeronautical satellite propagation characteristics, the physical mechanisms and parameters that limit the data throughput. We have shown that the aeronautical satellite propagation model and its long-term statistical parameters can be derived, using the aircraft navigational data and satellite global positions together with some meteorological data. We have presented a receiver architecture that estimates and rectifies the shortterm propagation characteristics making use of a-priori knowledge determined from the propagation model as derived. It has been shown that this receiver architecture performs well in an iterative structure, by progressively improving the received signal quality. The results show that the proposed method is very promising and that introduction of this technology into an aeronautical satellite communications system would improve the reliability of mission-critical safety services, as well as improving the commercial viability for broadband services to aircraft in the future. 


\section{REFERENCES}

[1] P. A. Bello, "Aeronautical Channel Characterization", IEEE Trans. Comms., vol. COM-21, no. 5, pp. 548-563, May. 1973.

[2] ITU-R Rec. 682-1, "Propagation Data required for the Design of Earth-Space Aeronautical Mobile Telecommunication Systems", 1992.

[3] Y. Karasawa and T. Shiokawa, "Characteristics of $L$-Band Multipath Fading Due to Sea Surface Reflection", IEEE Trans. Antennas Propagat., vol. AP-32, no. 6, pp. 618-623, Jun. 1984.

[4] Y. Karasawa and T. Shiokawa, "A Simple Prediction Method for $L$-Band Multipath Fading in Rough Sea Conditions", IEEE Trans. Comms., vol. 36, no. 10, pp. 1098-1104, Oct. 1988.

[5] B. G. Smith, "Geometrical Shadowing of a Random Rough Surface", IEEE Trans. Antennas Propagat., vol. AP-15, no. 5, pp. 668-671, Sep. 1967.

[6] D. E. Barrick, "Rough Surface Scattering Based on the Specular Point Theory", IEEE Trans. Antennas Propagat., vol. AP-16, no. 4, pp. 449-454, Jul. 1968.

[7] D. E. Barrick and E. Bahar, " Rough Surface Scattering Using Specular Point Theory”, IEEE Trans. Antennas Propagat., vol. AP-29, no. 5, pp. 798-800, Sep. 1981.

[8] D. E. Barrick, " Grazing Behavior of Scatter and Propagation Above Any Rough Surface", IEEE Trans. Antennas Propagat., vol. 46, no. 1, pp. 73-83, Jan. 1998.

[9] Y. Karasawa, T. Kuroda and H. Iwai, "Cycle Slip in Clock recovery on Frequency-Selective Fading Channels", IEEE Trans. Comms., vol. 45, no. 3, pp. 376-383, Mar. 1997.

[10] Y. Karasawa, T. Kuroda and H. Iwai, "The Equivalent Transmission-Path Model-A Tool for Analysing Error Floor Characteristics Due to Intersymbol Interference in NakagamiRice Fading Environments", IEEE Trans. Veh. Technol., vol. 46, no. 1, pp. 194-202, Feb. 1997.

[11] P. Beckmann and A. Spizzichino, "The Scattering of Electromagnetic waves from Rough Surfaces", Artech House, 1987.

[12] S. Verdu, “Multi User Detection", Cambridge Univ. Press, 1998.

[13] A. Jahn, M. Richharia, M. Alvarez, P. Fines and N. Kaluvala, "Aeronautical Channel Model for Broadband L-Band Satellite Communications", in Proc. 23 ${ }^{\text {rd }}$ Comm. Satellite Sys. Conf, Sept. 2005. 